\author{
К. А. Кудрявцев \\ Поволжский государственный технологический университет, \\ г. Йошкар-Ола, Республика Марий Эл, Россия
}

В статье для определения нового вектора развития антимонопольного регулирования исследуется механизм его трансформации. В процессе исследования доказывается научная гипотеза - антимонопольное регулирование трансформируется параллельно смене моделей государственного регулирования экономики и в зависимости от экономического цикла используется государством как инструмент влияния на результаты функционирования товарных рынков с ограниченной и развитой конкуренцией. Вскрытые причинноследственные связи, определяющие механизм трансформации, позволили выделить фазы развития антимонопольного регулирования в мире и России. В целях преодоления отсталости экономики и реализации Национального плана развития конкуренции в Российской Федерации для новой фазы антимонопольного регулирования разработаны концептуальные основы, отраженные в модели баланса интересов, с соответствующими ключевыми показателями. Представленная модель является развитием Гарвардской парадигмы «структура - поведение - результат», которая также впоследствии дополнилась базовыми условиями и государственной политикой, в систему которой входит в том числе и антимонопольное регулирование. Следовательно, с учетом разработанных концептуальных основ при государственном регулировании товарных рынков первично определение баланса интересов субъектов рынка - государства, хозяйствующих субъектов и потребителей, который формирует их структуру, поведение и, как следствие, результат.

Ключевые слова: конкуренция, монополия, баланс интересов, механизм, концепция, хозяйствующий субъект, потребитель.

\title{
TRANSFORMATION OF THE INSTITUTION OF ANTI-TRUST REGULATION (MECHANISM AND CONCEPT)
}

\author{
Konstantin A. Kudryavtsev \\ Volga State University of Technology, Yoshkar-Ola, \\ Republic of Mariy El, Russia
}

To find a new vector of developing anti-trust regulation the article researches mechanism of its transformation. In the process of research the academic hypothesis is proved, i. e. anti-trust regulation transforms in line with the change of models of state economy regulation and subject to the economic cycle is used by state as a tool of influencing the results of goods markets functioning with limited and developed competition. The disclosed causeand effect links determining the transformation mechanism made it possible to identify stages of developing antitrust regulation in the world and in Russia. In order to overcome backwardness of economy and implement the National plan of developing competition in the Russian Federation conceptual principles were developed for the new phase of anti-trust regulation, which are shown in the model of interest balance with the respective key indicators. The presented model is the development of the Harvard paradigm 'structure - behavior - result' that was later supplemented with basic conditions and state policy, whose system includes anti-trust regulation. Therefore, with regard to designed conceptual principles with state regulation of goods market what is the most important is the balance of interests of entities of market - state, business entities and customers that form the structure, behavior and result.

Keywords: competition, monopoly, anti-trust regulation, balance of interests, mechanism, concept, business entity, customer. 


\section{Введение}

$\Pi$ оиск, разработка и принятие в России новой модели государственного регулирования экономики невозможно без развития конкуренции на товарных рынках, т. е. фактического пересмотра перманентно занимаемых долей государственными монополиями, естественными монополиями, крупным и средним бизнесом. В Национальном плане развития конкуренции в Российской Федерации на 2018-2020 годы (Указ Президента Российской Федерации от 21 декабря 2017 г. № 618 «Об основных направлениях государственной политики по развитию конкуренции») определены ключевые показатели по развитию конкуренции: наличие во всех отраслях экономики хозяйствующих субъектов, снижение количества нарушений антимонопольного законодательства органами власти, увеличение участия субъектов малого предпринимательства и социально ориентированных некоммерческих организаций в госзакупках. Правительству Российской Федерации, федеральным органам исполнительной власти и Федеральной антимонопольной службе дан ряд поручений в указанном направлении.

Имплементация Национального плана приведет к необходимой трансформации и антимонопольного регулирования, главным недостатком которого является его развитие при отсутствии концептуальных основ, которым необходимо следовать. Данный факт подтверждается как отсутствием в трудах ученых разработанных концептуальных основ антимонопольного регулирования, так и указанием И. Р. Курнышевой в статье «Государственное регулирование структурных преобразований в условиях конкуренции» на необходимость разработки концептуальных и методологических предпосылок совершенствования антимонопольной деятельности [3].

Для достижения требуемого результата и определения нового вектора развития антимонопольного регулирования в первую очередь необходимо исследовать ме- ханизм его трансформации. С этой целью нами был проведен исторический анализ развития антимонопольного регулирования в контексте смены моделей государственного регулирования экономики и технологических укладов.

\section{Механизм трансформации}

\section{антимонопольного регулирования}

Научная гипотеза исследования - антимонопольное регулирование трансформируется параллельно смене моделей государственного регулирования экономики и в зависимости от экономического цикла используется государством как инструмент влияния на результаты функционирования товарных рынков с ограниченной и развитой конкуренцией.

Для доказательства данной научной гипотезы и раскрытия механизма трансформации антимонопольного регулирования сопоставим смену технологических укладов с изменениями моделей государственного регулирования экономики и антимонопольного регулирования.

Исходя из данных, приведенных в таблице, можно выделить следующие фазы антимонопольного регулирования:

1) эмбриональная фраза - предпосылки возникновения антимонопольного регулирования в отдельных отраслях. Продолжительность - 98 лет (1791-1889);

2) фаза начала развития - появление антимонопольного законодательства и его малая эффективность. Продолжительность - 47 лет (1889-1936);

3) фраза широкого распространения - ужесточение антимонопольного законодательства, большая роль государства в регулировании рынков. Продолжительность 46 лет (1936-1982);

4) фраза либерализации - ослабление антимонопольного законодательства, возрождение рыночного механизма. Продолжительность - с 1982 г. по настоящее время;

5) фаза усиления роли государства в регумировании рынков (прогноз). Начало - 20182020 гг. 


\section{Фазы развития антимонопольного регулирования в контексте смены технологических укладов и моделей государственного регулирования экономики}

\begin{tabular}{|c|c|c|c|}
\hline Технологический уклад* & $\begin{array}{c}\text { Модель государственного } \\
\text { регулирования экономики } \\
\end{array}$ & Антимонопольное регулирование & Фаза \\
\hline \multicolumn{4}{|c|}{$\begin{array}{c}\text { Предпосылки антимонопольного регулирования в виде решений судов и отдельных законодательных актов, } \\
\text { направленных на регулирование и пресечение проявлений монополизма в отдельных отраслях }\end{array}$} \\
\hline $\begin{array}{l}\text { I. 1770-1830 гг. } \\
\text { Текстильная промыш- } \\
\text { ленность, водяной двига- } \\
\text { тель, выплавка чугуна, } \\
\text { обработка железа }\end{array}$ & $\begin{array}{l}\text { Классическая политическая экономия } \\
\text { XVIII в., А. Смит. } \\
\text { Принцип laissez faire (предоставить свобо- } \\
\text { ду деятельности, не мешать) }\end{array}$ & 1791 г. - закон Ле Шапелье (Франция) & 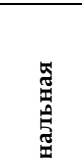 \\
\hline $\begin{array}{l}\text { II. 1830-1880 гг. } \\
\text { Паровой двигатель, же- } \\
\text { лезные дороги, машино- } \\
\text { строение, черная метал- } \\
\text { лургия }\end{array}$ & \multirow{2}{*}{$\begin{array}{l}\text { Неоклассическая модель } \\
\text { XIX в. - 30-е гг. XX в., Ж. Б. Сэй. } \\
\text { В рыночной экономике кризис перепроиз- } \\
\text { водства невозможен, так как спрос и пред- } \\
\text { ложение всегда уравновешиваются. Произ- } \\
\text { водство само создает достаточный спрос, } \\
\text { происходит саморегулирование рынка }\end{array}$} & & तั \\
\hline $\begin{array}{l}\text { III. 1880-1930 гг. } \\
\text { Электротехническое и } \\
\text { тяжелое машинострое- } \\
\text { ние, неорганическая } \\
\text { химия }\end{array}$ & & $\begin{array}{l}1889 \text { г. - первый в истории антимонопольный } \\
\text { закон - закон доминиона (Канада). } \\
1890 \text { г. - Акт Шермана (США). } \\
1914 \text { г. - закон «О Федеральной торговой комис- } \\
\text { сии» (США). } \\
1914 \text { г. - закон Клейтона (США). } \\
1923 \text { г. - первый европейский антимонопольный } \\
\text { закон, запрещавший картельные соглашения } \\
\text { (Германия) }\end{array}$ & 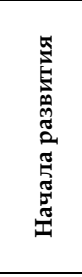 \\
\hline $\begin{array}{l}\text { IV. 1930-1970 гг. } \\
\text { Автомобиле-, тракторо- } \\
\text { строение, цветная метал- } \\
\text { лургия, органическая } \\
\text { химия, нефтехимия }\end{array}$ & $\begin{array}{l}\text { Кейнсианство } \\
\text { 1930-1970 гг., Дж. М. Кейнс. } \\
\text { Создание платежеспособного эффективно- } \\
\text { го спроса. Определение функциональной } \\
\text { зависимости между занятостью, потребле- } \\
\text { нием и инвестициями }\end{array}$ & $\begin{array}{l}1936 \text { г. - закон Робинсона - Пэтмэна (США). } \\
1938 \text { г. - закон Уилера-Ли (США). } \\
1950 \text { г. - закон Селлера - Кефовера (США). } \\
1952 \text { г. - Акт Макгайра (США). } \\
1 \text { января } 1958 \text { г. - Римский договор о создании } \\
\text { Европейского экономического общества. } \\
1962 \text { г. - Акт о гражданском антитрестовском } \\
\text { процессе (США). } \\
\text { Преобладание взглядов Гарвардской экономической } \\
\text { иколы }\end{array}$ & 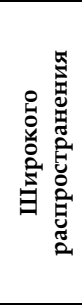 \\
\hline $\begin{array}{l}\text { V. 1970-2010 гг. } \\
\text { Электронная промыш- } \\
\text { ленность, оптико- } \\
\text { волоконная техника, } \\
\text { роботостроение, произ- } \\
\text { водство и переработка } \\
\text { газа, информационные } \\
\text { услуги }\end{array}$ & $\begin{array}{l}\text { Неоклассический синтез } \\
\text { Дж. Хикс, Ф. Модильяни, П. Самуэльсон. } \\
\text { Интеграция теоретических положений } \\
\text { неоклассической и кейнсианской школ. } \\
\text { Неоконсервативная модель государствен- } \\
\text { ного регулирования: монетаризм } \\
\text { (М. Фридман), теория экономики предло- } \\
\text { жения (А. Лаффер, Дж. Гилдер) и рацио- } \\
\text { нальных ожиданий (Дж. Мут, Р. Лукас, } \\
\text { Л. Реппинг). Преобладание косвенных } \\
\text { методов государственного регулирования } \\
\text { через денежно-кредитную и бюджетно- } \\
\text { налоговую политику. Меры государствен- } \\
\text { ного регулирования направлены на стиму- } \\
\text { лирование эффективного спроса, воссозда- } \\
\text { ние классического механизма накопления } \\
\text { и возрождение рыночного механизма, } \\
\text { обеспечение свободы частного предпри- } \\
\text { нимательства. } \\
\text { Новая институциональная экономика } \\
\text { Д. Норт. } \\
\text { Соотносительность экономических инсти- } \\
\text { тутов и личных интересов экономических } \\
\text { агентов }\end{array}$ & $\begin{array}{l}1982 \text { г. - закон о компаниях, специализирующих- } \\
\text { ся на экспорте (США). } \\
1984 \text { г. - новые правила антитрестовского управ- } \\
\text { ления (США). } \\
\text { Данные законы в США были сформированы под } \\
\text { влиянием взглядов представителей Чикагской } \\
\text { экономической школы, которые критически отно- } \\
\text { сились к государственному вмешательству в ры- } \\
\text { ночные отношения. Создание } 1 \text { января } 1995 \text { г. } \\
\text { ВТО обусловило принятие отдельных законов о } \\
\text { защите конкуренции в большинстве стран мира. } \\
1990 \text { г. - Постановление Совета министров РСФСР } \\
\text { № } 344 \text { «Вопросы Государственного комитета по } \\
\text { антимонопольной политике и поддержке новых } \\
\text { экономических структур» и Временное положе- } \\
\text { ние о Государственном комитете по антимоно- } \\
\text { польной политике и поддержке новых экономи- } \\
\text { ческих структур. Начало развития антимоно- } \\
\text { польного законодательства в России. } \\
2006 \text { г. - Закон о защите конкуренции в России. } \\
2007 \text { г. - Закон о конкуренции ЕС (положения } \\
\text { Договора о функциоировании (ТFЕU) и Догово- } \\
\text { ра о Европейском союзе (ТЕU)) }\end{array}$ & 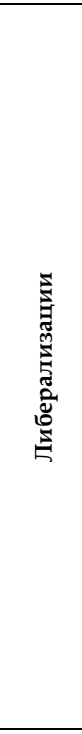 \\
\hline $\begin{array}{l}\text { VI. 2010-2050 гг. } \\
\text { Нанотехнологии, клеточ- } \\
\text { ные технологии, генная } \\
\text { инженерия }\end{array}$ & 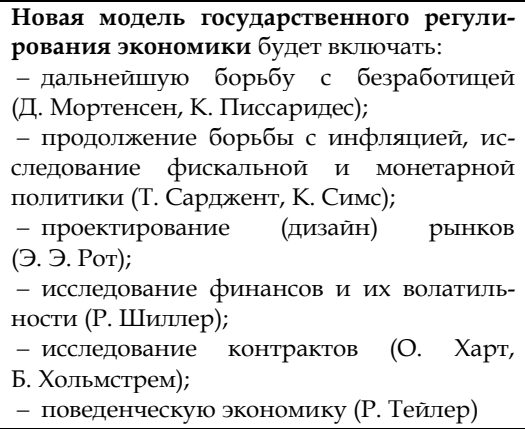 & $\begin{array}{l}\text { Сдвиг антимонопольного законодательства в } \\
\text { сторону информационного общества - регулиро- } \\
\text { вание конкурентных отношений в сети Интернет } \\
\text { (деятельность сайтов, интернет-магазинов), регу- } \\
\text { лирование контрактных отношений, поведения } \\
\text { субъектов рынка. } \\
\text { Создание в России в } 2015 \text { г. мегарегулятора за счет } \\
\text { консолидации полномочий по антимонопольно- } \\
\text { му, тарифному регулированию, контролю в сфе- } \\
\text { ре государственного оборонного заказа }\end{array}$ & 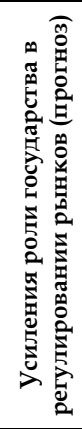 \\
\hline
\end{tabular}

* Составлено по: [4]. 
Правительство стран мира в зависимости от экономического цикла и, как следствие, роста или кризисного состояния экономики использует антимонопольное регулирование как инструмент влияния на результаты функционирования товарных рынков с ограниченной и развитой конкуренцией. В фазе роста антимонопольное законодательство, как правило, усиливается, в фазе спада и депрессии - ослабляется, идет переход к свободному рынку.

На основании вышеприведенного анализа и синтеза антимонопольного регулирования в сочетании с моделями государственного регулирования экономики и со сменой технологических укладов нами выявлены причинно-следственные связи, которые определяют механизм трансформации института антимонопольного регулирования и доказывают научную гипотезу исследования.

В России антимонопольное регулирование начало развиваться с 1990 г., когда на последнем XXVIII съезде КПСС было принято принципиальное решение о необходимости развития рыночной экономики, конкуренции и предпринимательства, которые откроют простор деловой активности и инициативе людей ${ }^{1}$.
Можно выделить следующие фазы развития антимонопольного регулирования в России (рис. 1):

1) фаза начала развития - появление первых антимонопольных законов, ряд реорганизаций антимонопольного комитета, образование Министерства по антимонопольной политике и поддержке предпринимательства, его малая эффективность. Продолжительность - 14 лет (с 1990 по 2004 г.);

2) фраза широкого распространения - реорганизация Министерства по антимонопольной политике и поддержке предпринимательства в ФАС России, ужесточение антимонопольного законодательства, его распространение во многие сферы деятельности. Продолжительность - 8 лет (с 2004 по 2011 г.);

3) фаза либерализации - послабления антимонопольного законодательства по ряду направлений, возрождение рыночного механизма. Продолжительность - с 2012 г. по настоящее время;

4) фаза усиления роли государства в регумировании рынков (прогноз). Начало - 20182020 гг. Предпосылки данной фазы - создание с 21 июля 2015 г. на основе ФАС единого мегарегулятора за счет передачи полномочий от Федеральной службы по тарифам Российской Федерации.

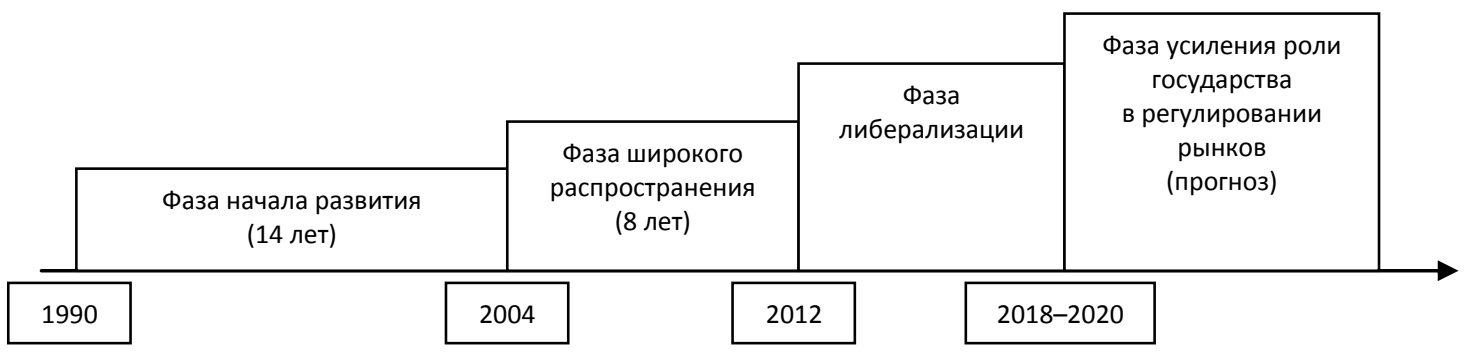

Рис. 1. Фазы развития антимонопольного регулирования в России

Следовательно, те фазы, которые западные страны проходили более 40 лет, в России заняли от четырнадцати лет и менее. Первые две фазы прошли в рамках пятого технологического уклада, и высокие темпы их прохождения были связаны с отсталостью России в этой сфере. Третья фаза либерализации соответствует переходу к шестому технологическому укладу.

Таким образом, фазы развития антимонопольного регулирования в России совпадают с фазами, прошедшими в развитых

1 URL: http://soveticus5.narod.ru/85/xxviii_1.htm 
странах, и сегодня это развитие соответствует общемировым тенденциям.

\section{Концептуальные основы} антимонопольной деятельности

Раскрыв механизм трансформации антимонопольного регулирования и выделив его фазы, можно сделать вывод, что состав данного института регулирования в различных странах зависит от экономических условий и позиции государственной вла- сти. Следовательно, в Российской Федерации концепция государственного антимонопольного регулирования должна основываться на его концептуальном представлении как сложной системы общественных отношений государства, хозяйствующих субъектов и потребителей. Баланс интересов между указанными субъектами можно изобразить в виде графической модели равнобедренного треугольника (рис. 2).

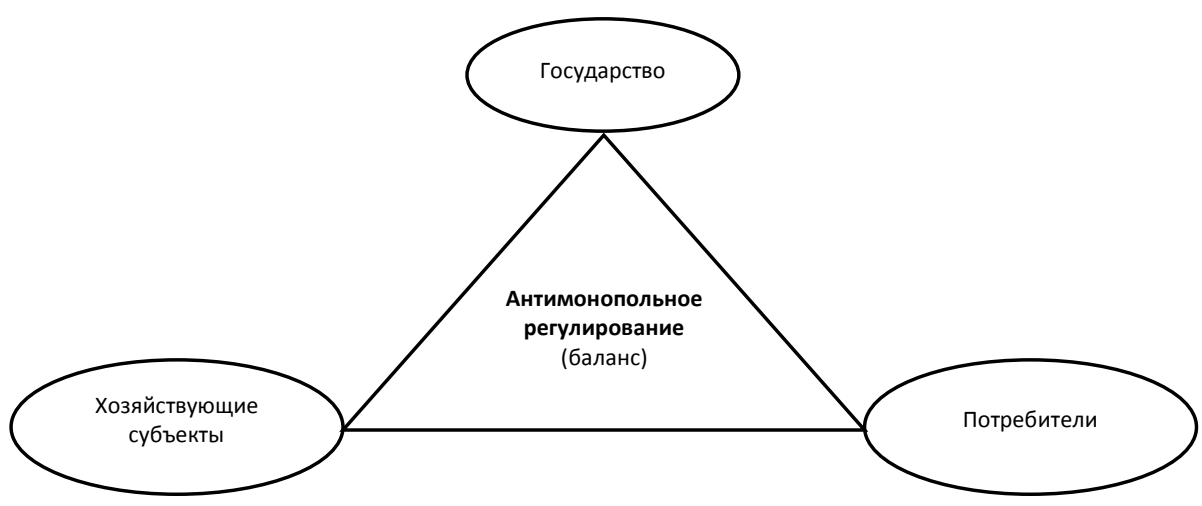

Рис. 2. Графическая модель баланса интересов в государственном антимонопольном регулировании

Приведенным в модели субъектам свойственны определенные цели, для каждой из которых разработаны ключевые показатели (рис. 3).

\section{ГОСУДАРСТВО}

Эффективность: налоговые отчисления, штрафы.

Справедливость: программы развития, субсидии, субвенции, дотации.

Стабильность: конкуренция на рынке, структура рынка (количество предприятий малого, среднего и крупного бизнеса)

ХОЗЯЙСТВУЮЩИЕ СУБЪЕКТЫ

Эффективность на товарных рынках: доля фирмы на рынке, уровень концентрации, барьеры входа и выхода на рынок

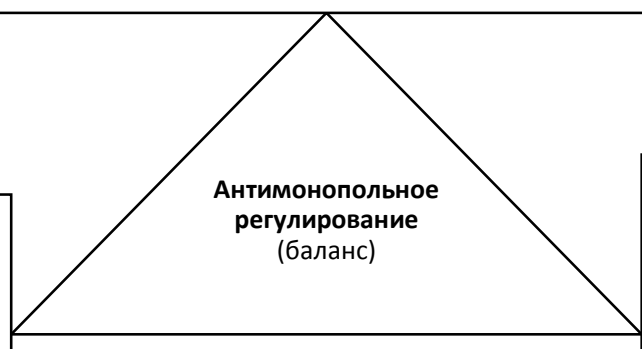
предложение на рынке (количество фирм, производящих один товар), цена на товар, наличие товаров-заменителей

Рис. 3. Модель баланса интересов в государственном антимонопольном регулировании 
Таким образом, ключевые показатели, на которые влияет антимонопольное регулирование, определяют показатели эффективности государства, хозяйствующих субъектов и потребителей. Разработанная модель является развитием гарвардской парадигмы «структура - поведение - результат», которая также впоследствии дополнилась базовыми условиями и государственной политикой, в систему которой входит в том числе и антимонопольное регулирование. Следовательно, с учетом разработанных концептуальных основ при государственном регулировании товарных рынков первично определение баланса интересов государства, хозяйствующих субъектов и потребителей, который формирует структуру, поведение и, как следствие, результат.

Цели антимонопольного регулирования для трех элементов разработанной модели:

1. Государство - развитие хозяйствующих субъектов в благоприятной конкурентной среде, защита от несовершенной конкуренции. Как следствие, выполняются глобальные цели в государственном регулировании:

- эффективность, т. е. наличие эффективно функционирующего производства, результатом которого является пополнение бюджета в виде налоговых отчислений предпринимателей. Наряду с указанным несоблюдение антимонопольного законодательства предполагает наложение серьезных штрафов, в том числе и оборотных (от выручки за прошлый год), что также является одним из источников консолидированного бюджета страны;

- справедливость, т. е. государство перераспределяет доходы через собранные налоги. С этой целью оно использует такие инструменты, как программы развития, субсидии, субвенции, дотации;

- стабильность - государственное регулирование обеспечивает конкуренцию на рынке с целью формирования определенной структуры рынка: количества предприятий малого, среднего и крупного бизнеса.

2. Хозяйствующие субъекты - защита их интересов от недобросовестных действий иных хозяйствующих субъектов, в том числе естественных монополий и органов власти, что позволяет им более эффективно функционировать на товарных рынках.

3. Потребители - антимонопольное регулирование, которое сохраняет потребительское благополучие посредством защиты интересов граждан, например, от манипулирования ценами монополистами или хозяйствующими субъектами. Высокий уровень конкуренции на товарных рынках ведет к сбалансированности цен на них и расширению выбора для потребителя.

Таким образом, для эффективной реализации Национального плана развития конкуренции в Российской Федерации на 2018-2020 годы необходимо произвести совершенствование института антимонопольного регулирования с учетом разработанных концептуальных основ.

\section{Заключение}

Конвергенция государства, хозяйствующих субъектов и потребителей должна стать основой как новой модели государственного регулирования экономики, так и новой фазы развития антимонопольного регулирования. Недостаточность данной связи между приведенными субъектами выступает одним из ключевых факторов, препятствующих обеспечению национальной безопасности и снижению социальной напряженности в обществе. Достижение нового уровня в государственном регулировании экономики, преодоление ее отсталости в условиях зарождения нового технологического уклада требуют переосмысления сложившейся парадигмы. Поэтому Национальный план развития конкуренции сегодня является важным детерминантом в целях укрепления национальной экономики, дальнейшего развития конкуренции и недопущения монополистической деятельности. 


\section{Список литературы}

1. Институты конкурентной политики в регулировании новой индустриализации / отв. ред. И. Р. Курнышева; науч. ред. А. Е. Городецкий. - М. : ИЭ РАН, 2012.

2. Князева И. В., Лукашенко О. А. Трансформация антимонопольной политики в политику защиты конкуренции в современных экономических условиях : монография. - Новосибирск : Изд-во СибАГС : Изд-во НГТУ, 2011.

3. Курнышева И. Р. Государственное регулирование структурных преобразований в условиях конкуренции // Вестник Института экономики Российской академии наук. 2017. - № 5. - С. 23-35.

4. Нанотехнологии как ключевой фактор нового технологического уклада в экономике : монография / под ред. С. Ю. Глазьева, В. В. Харитонова. - М. : Тровант, 2009.

\section{References}

1. Instituty konkurentnoy-politiki $\mathrm{v}$ regulirovanii novoy industrializacii [Institutes of Competitive Politics in the Regulation of the New Industrialization], edited by I. R. Kurnysheva, A. E. Gorodeckiy. Moscow, IE RAS, 2012. (In Russ.).

2. Knyazeva I. V., Lukashenka O. A. Transformaciya antimonopolnoy politiki v politiku zashchity konkurencii $\mathrm{v}$ sovremennyh ehkonomicheskih usloviyah [Transformation of the Antimonopoly Policy into the Policy of Protection of Competition in the Current Economic Conditions, monograph]. Novosibirsk, Publishing house of SibAPS, Publishing house of NSTU, 2011. (In Russ.).

3. Kurnysheva I. R. Gosudarstvennoe regulirovanie strukturnyh preobrazovaniy v usloviyah konkurencii [State Regulation of Structural Changes in a Competitive Environment]. Vestnik Instituta ekonomiki Rossiyskoy akademii nauk [Bulletin of the Institute of Economics of the Russian Academy of Sciences], 2017, No. 5, pp. 23-35. (In Russ.).

4. Nanotekhnologii kak klyuchevoy faktor novogo tekhnologicheskogo uklada $v$ ekonomike, monografiya [Nanotechnology as a Key Factor in the New Technological Order in the Economy, monograph], edited by S. Yu. Glaz'ev, V. V. Haritonov. Moscow, Trovant, 2009. (In Russ.).

\section{Сведения об авторе}

\author{
Константин Александрович Кудрявцев \\ кандидат экономических наук, доцент \\ кафедры экономики и организации \\ производства ПГТУ. \\ Адрес: ФГБОУ ВО «Поволжский \\ государственный технологический \\ университет», 424000, Республика Марий Эл, \\ г. Йошкар-Ола, пл. Ленина, д. 3. \\ E-mail: KudryavcevKA@volgatech.net
}

\section{Information about the author}

\section{Konstantin A. Kudryavtsev}

PhD, Assistant Professor of the Department for Economy and Production Organization of the VSUT.

Address: Volga State University of Technology, 3 Lenin Sq., Yoshkar-Ola, 424000, Republic of Mariy El, Russian Federation.

E-mail: KudryavcevKA@volgatech.net 